\title{
DNA Interaction with Catanionic Vesicles
}

\author{
Rita S. Dias, ${ }^{\dagger, \dagger}$ Björn Lindman, ${ }^{\dagger, *}$ and Maria G. Miguel ${ }^{*, \dagger}$ \\ Chemistry Department, University of Coimbra, 3004-535 Coimbra, Portugal, and Physical Chemistry 1, \\ Center for Chemistry and Chemical Engineering, P.O. Box 124, 22100 Lund, Sweden
}

Received: February 11, 2002; In Final Form: May 9, 2002

\begin{abstract}
DNA-cationic liposome complexes as possible vehicles for gene delivery is currently an important issue. In this work, the interaction between DNA and thermodynamically stable, spontaneously formed, catanionic vesicles with a net positive charge is studied. A phase map was drawn for the aqueous system of DNA and positively charged vesicles, composed of CTAB (cetyltrimethylammonium bromide) and SOS (sodium octyl sulfate), and showed, as expected, a strong associative phase behavior with the formation of a precipitate. A two-phase region was observed over all the studied concentrations. For DNA - surfactant mixing ratios, [DNA]/ $\left[\mathrm{S}^{+}\right]$below 1.3 by charge, we found, by optical and electron microscopy, a coexistence between undisturbed vesicles and DNA-surfactant complexes. In samples with a higher excess of DNA, only DNA-vesicle complexes were observed in solution. The structure of these complexes was studied by both small-angle X-ray diffraction (SAXS) and cryogenic transmission electron microscopy (cryo-TEM), and a short-range lamellar structure composed of amphiphile bilayers with DNA molecules ordered and packed between these stacks was found. This type of structure has already been mentioned in the literature as being the most frequently found structure for DNA-liposome mixtures and shows that the vesicles we used, having major advantages with respect to preparation and stability, have similar behavior and can thus be successfully used as model systems. We observed, however, an interesting difference in comparison with previously studied systems. Thus, the addition of DNA in excess to the samples leads not to the coexistence of DNA-vesicle complexes and DNA, as observed before, but to a probable inclusion of DNA in excess in the complexes and therefore to a coexistence of complexes and anionic surfactant micelles expelled from the bilayers.
\end{abstract}

\section{Introduction}

Gene therapy has been introduced as one of the most promising new therapeutical models for the treatment of a number of genetic diseases. These treatments consist basically of the attempt to transport DNA or other genetic material through the cell and its release into the nucleus. One of the most popular therapies consists of the use of viral vectors because of their known capability of delivering their DNA to cells. However, there are several problems arising from their use. Viral vectors will always have limitations on safety and production. Also, their use has the disadvantages of the DNA size limit because a viral capsid holds only about 40 kilobase pairs (kbp), and it can be destroyed by the organism's immune system. An interesting alternative appeared in the late 1980 s with the use of cationic liposomes for gene delivery and tranfection. ${ }^{1}$ The cationic vesicles, composed of a binary mixture of a cationic lipid and a neutral one, were used to compact DNA, decreasing its size. Also, by forming complexes with DNA that carried positive charges, it was easier to approach and penetrate the cell membrane. This method, "lipofection", has then the advantage of no size limit for DNA, but it has still very low transfection rates. Even so, more than 50 commercial kits for transfection have appeared on the market. $^{2}$ The general belief that DNA compaction and the structure of the formed complexes between DNA and cationic liposomes, lipoplexes, are important aspects induced a number of physicochemical studies on several of these systems.

* Corresponding author. E-mail: mgmiguel@ci.uc.pt.

¿ University of Coimbra.

$¥$ Center for Chemistry and Chemical Engineering.
It is also believed that the lipoplex size distribution and structure depend on the way of mixing the components, the technique used to observe them, as well as, of course, the lipids used. ${ }^{3}$ One can find in the literature the description of mainly three types of complexes: one with a short-range lamellar structure composed of flat lipid bilayers and DNA packed between them, ${ }^{4-9}$ another where the DNA molecules are encapsulated inside a lipid bilayer, forming cylindrical complexes that are closely packed on a hexagonal network, ${ }^{10}$ and finally the so-called "bead on a string" complexes, where DNA attaches to the outer surface of the positively charged liposomes. ${ }^{11,12}$ The first two structures are more interesting from a DNA compaction and gene therapy efficiency point of view, and the difference in the complex formation is referred to the chosen neutral "helper lipid". One can, in fact, by changing the neutral lipid, induce a transition between the lamellar and the hexagonal structures. ${ }^{10}$ It has been argued $^{13}$ that the third structure suggested was induced by the used technique (freezefracture electron microscopy) and that the aggregates are, in fact, of the same type as the ones already described as lamellar.

Despite all these studies, there exists still little information in the literature about the physical chemistry of DNA interactions with amphiphiles. The compaction of DNA, which is a very important parameter for gene-transfer efficiency, is still not quite understood. With this paper, we make an attempt to bring some ideas and conclusions that might be useful to other researchers in the field.

In our work, we study the interactions between DNA and synthetic positively charged catanionic vesicles, giving special attention to the structure of the formed complexes. 


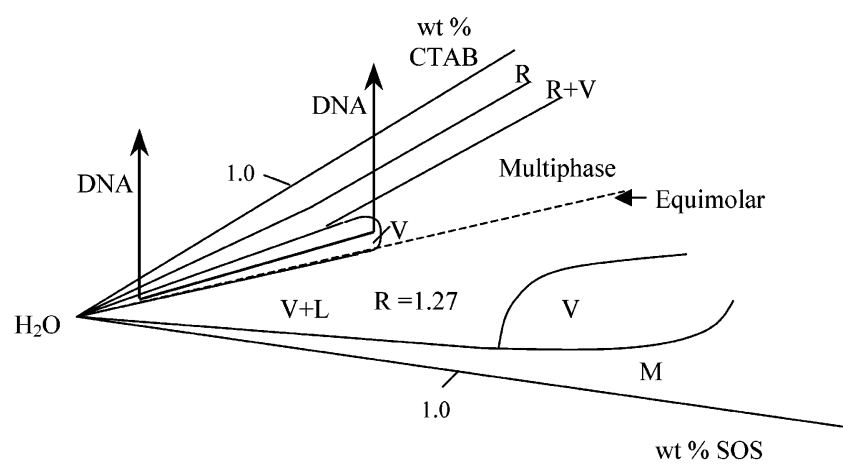

Figure 1. Schematic representation of the approach used for the study of the phase behavior of the aqueous mixtures of DNA catanionic CTAB-rich vesicles.

Catanionic mixtures are defined as mixtures of cationic and anionic surfactants. ${ }^{14}$ These pseudoternary aqueous mixtures exhibit richer phase behavior and interfacial properties when compared with those of the individual surfactants. An example of this is the formation of vesicles that are not observed when only one of the surfactants is present in aqueous solution. ${ }^{15}$ Catanionic vesicles are believed to be thermodynamically stable because they are formed spontaneously and reversibly and remain stable for a long period of time. ${ }^{16}$ The application of these systems in biophysics and biochemistry, pharmacology and drug delivery, and medicine and cosmetics is currently under consideration.

The system used in this work was the aqueous mixture of cetyltrimethylammonium bromide (CTAB) and sodium octyl sulfate (SOS) previously studied by Kaler et al.; ${ }^{15,17}$ we were interested in the positively charged vesicles.

Several studies on the single-molecule visualization of the interactions between DNA and liposomes have been presented. ${ }^{18-20}$ In previous work, ${ }^{21}$ we studied the interaction of DNA with positively charged catanionic vesicles, with a focus on the effect of the vesicles on the DNA molecule. We observed, by fluorescence microscopy, the DNA conformational change from coil to globule and its adsorption onto the surface of the positive vesicles. We then became interested in the effect of DNA on the vesicles and started this work with the investigation of the phase behavior of the aqueous DNA-CTAB/SOS system. The phases and their boundaries were determined by optical and electron microscopy. We found strong associative behavior with the formation of a precipitate. The structure of the precipitate, the DNA-catanionic vesicle complexes, was evaluated by X-ray diffraction and electron microscopy.

\section{Experimental Section}

Materials. The surfactants, cetyltrimethylammonium bromide (CTAB) and sodium octyl sulfate (SOS), were obtained from Sigma and Merck, respectively. Both were used as received. DNA type XIV from herring testes was purchased from Sigma without further indication. Its molecular weight was determined by gel electrophoresis and found to have a polydispersity value between 400 and 1000 base pairs, bp, with a center of distribution at ca. $700 \mathrm{bp}$. The DNA concentration was determined spectrophotometrically by considering the molar extinction coefficient of DNA bases to be equal to 6600 $\mathrm{M}^{-1} \mathrm{~cm}^{-1}{ }^{22}$ The ratio of the absorbance of the DNA stock solution at $260 \mathrm{~nm}$ to that at $280 \mathrm{~nm}$ was found to be 1.8 .

Sample Preparation. The determination of the phase diagram was made by adding DNA to the surfactant solution containing CTAB-rich vesicles, according to the schematic representation in Figure 1. The cationic vesicle stock solution was prepared by adding suitable volumes of stock solutions of CTAB and SOS. The resulting solution had the following composition, total surfactant concentration: $\mathrm{S}^{+}, 4.44 \mathrm{mM}$; surfactant mixing ratio, $[\mathrm{CTAB}] /[\mathrm{SOS}], R, 1.27$. All samples were prepared by dilution of the stock solution to the desired surfactant concentration and addition of the desired amount of DNA solution. The samples were prepared in corked tubes to facilitate subsequent experiments and were left, after slight mixing, to equilibrate for several days at $25{ }^{\circ} \mathrm{C}$, being regularly examined visually and between crossed polaroids. For small-angle X-ray scattering (SAXS) and cryogenic transmission electron microscopy (cryo-TEM) studies, samples were prepared following the same procedure in plastic Eppendorf tubes. The samples were centrifuged several times at $11000 \mathrm{rpm}$ for $60 \mathrm{~min}$ to remove as much water as possible from the precipitate. The supernatant was carefully removed for cryo-TEM studies, and the precipitate pellet was collected and analyzed by SAXS.

Phase Diagram Determination. Phase diagrams describe regions of existence of different phases and the equilibrium between them; for a three-component system, it is common to consider a ternary phase diagram. ${ }^{15}$ However, for the present case, because we are dealing with two electrolytes in water with no common ions, we have a four-component system that should be represented by a pyramid-shaped phase diagram ${ }^{23}$ or by trigonal bipyramids. ${ }^{24}$ Obviously, these three-dimensional representations contain more information than the ternary phase diagrams, but the complete establishment is extremely timeconsuming. So, for simplicity, we use a triangular representation that is a particular cut through the pyramidal body. ${ }^{25}$ When large amounts of water are present in the system (i.e., when we have dilute regimes), it is common to find further simplified phase diagrams as expansions of the water corner. ${ }^{17,26}$ This usually provides a better visualization.

This determination involved the preparation of over 50 samples and their observation for at least 6 months. The phase boundaries were determined by visual inspection of the samples in normal light and between crossed polaroids as well as by observations with light and electron microscopy. All samples were kept at $25^{\circ} \mathrm{C}$.

Light Microscopy. This technique was used to observe vesicles in solution. Because surfactant aggregates are not easily distinguished from the background if normal light is used in a normal apparatus, we used differential interface contrast (DIC) ${ }^{27}$ lenses as well as a camera connected to an image processor, so-called video-enhanced microscopy (VEM). ${ }^{28}$ The use of oilimmersion lenses also improves the resolution. A Zeiss Axion microscope was used, equipped with a $100 \times$ oil-immersed objective lens and DIC optics. The microscope image was digitized on a personal computer through a high-sensitivity SIT C-video camera and an image processor, Argus-20 (Hamamatsu Photonics, Japan). We used microscope slides and thin coverslips (No. 0) from Chance Propper, England.

Cryogenic Transmission Electron Microscopy (cryoTEM). The samples for cryo-TEM were prepared on a controlled-environment vitrification system ${ }^{29}$ at room temperature with controlled humidity (to minimize water loss) and temperature (to prevent temperature changes), allowing the specimen to relax for an indefinite time before being plugged into the cryogen. An $8-\mu \mathrm{L}$ drop of the solution was deposited on a lacy carbon film supported by a copper grid and gently blotted with filter paper to create a thin film suspended over the holes of the grid. The sample was then vitrified by rapidly plunging it into the cryogen containing liquid ethane at its melting temperature. To avoid the formation of ice, the vitrified 
a)

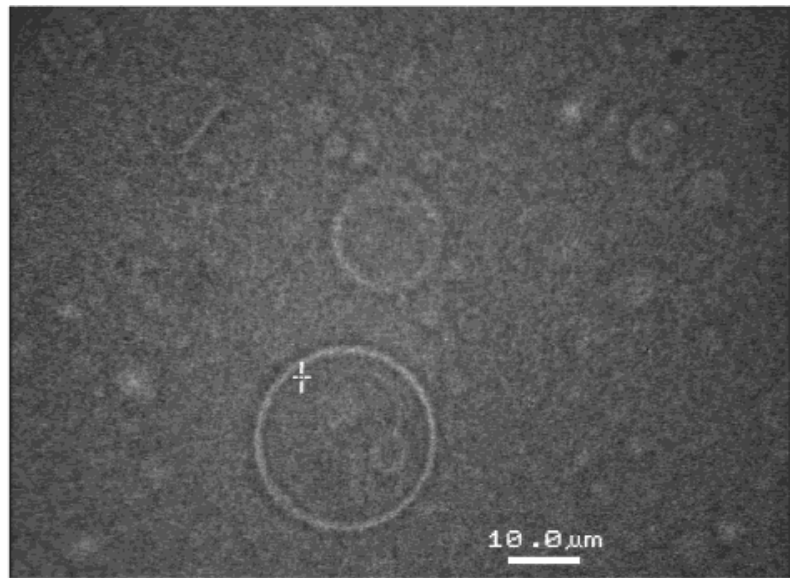

b)

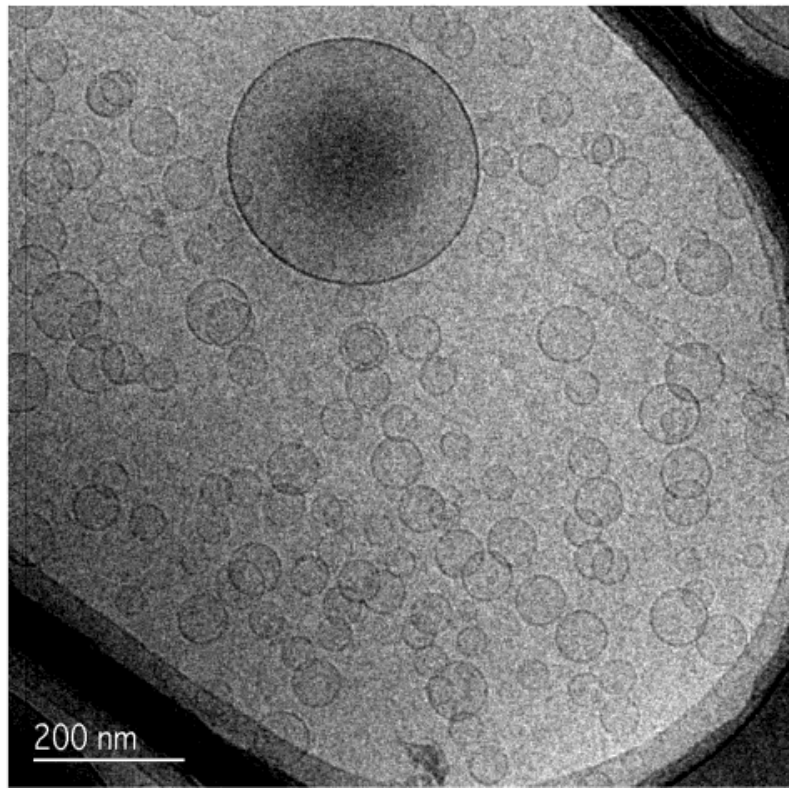

Figure 2. Light microscope and cryo-TEM images showing vesicles of CTAB-rich solutions in the aqueous CTAB-SOS system: (a) $\left[\mathrm{S}^{+}\right]$ $=3.77 \mathrm{mM}$, (b) $\left[\mathrm{S}^{+}\right]=2.27 \mathrm{mM}$. $[\mathrm{CTAB}] /[\mathrm{SOS}]=1.27$.

samples were stored and transferred onto the microscope under liquid nitrogen by means of a cold-stage transfer module (model 626, Gatan Inc., Warrendale, PA). A Philips CM 120 bio TWIN cryo electron microscope equipped with a postcolumn energy filter and an Oxford CT3500 cryoholder and its working station was used. The acceleration voltage was $120 \mathrm{kV}$, and the defocus was ca. $1 \mu \mathrm{m}$. Magnification of 55000 allowed a pixel width of $5 \AA$. Images were collected under low-dose conditions, with the dose being less that 0.1 electron per $\mathrm{nm}^{2}$. The images were recorded digitally with a CCD camera (Gatan MSC791).

Small-Angle X-ray Scattering (SAXS). SAXS measurements were performed on a Kratky compact small-angle system equipped with a position-sensitive detector (OED 50M, Mbraun, Austria) consisting of 1024 channels of $53.0-\mu \mathrm{m}$ width each. $\mathrm{Cu} \mathrm{K} \alpha$ radiation of wavelength $1.542 \AA$ was provided by a Seifert ID-300 X-ray generator operating at $50 \mathrm{kV}$ and $40 \mathrm{~mA}$. A $10-\mu \mathrm{m}$-thick Ni filter was used to remove the $\mathrm{K} \beta$ radiation, and a $1.5-\mathrm{mm} \mathrm{W}$ filter was used to protect the detector from the primary beam. The sample-to-detector distance was $277 \mathrm{~mm}$. To minimize the scattering from the air, the camera volume was kept under vacuum during the measurements. A Peltier element controlled the temperature within $25 \pm 0.1{ }^{\circ} \mathrm{C}$. A sample holder for pastelike and solid materials was used.

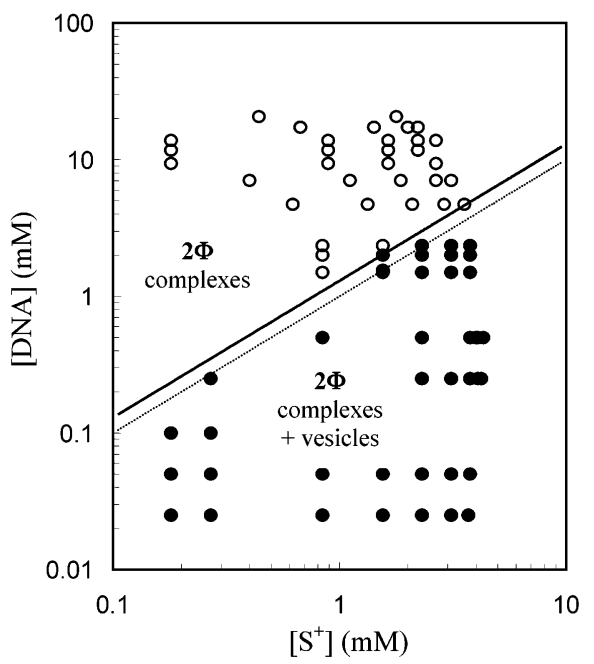

Figure 3. Phase map for the aqueous DNA-CTAB/SOS system at $25{ }^{\circ} \mathrm{C}$. The catanionic mixtures have a fixed composition, [CTAB]/ $[\mathrm{SOS}]=1.27$. A two-phase region with the formation of a precipitate is observed over all the studied concentrations. Below concentration ratios of $[\mathrm{DNA}] /\left[\mathrm{S}^{+}\right](\mathrm{D} / \mathrm{S}) 1.3$, we observed a coexistence of DNAvesicle complexes and undisturbed vesicles $(\bullet)$. For higher DNA concentrations, only complexes are present in solution $(O)$. The dashed line indicates the charge neutralization. $T=25^{\circ} \mathrm{C}$.

\section{Results}

Vesicle Solutions. To get an idea of the effect of DNA on these solutions, we started with a brief characterization of the polymer-free vesicle system. Very little has been reported in the literature about the CTAB-rich samples concerning this system $^{15,17}$. Reference was made only to spherical unilamellar vesicles with approximately $100-300 \mathrm{~nm}$ in diameter in coexistence with micelles. ${ }^{15}$

We could, by optical microscopy, also see the existence of a large number of polydisperse vesicles (Figure 2a) with a smooth spherical shape and an average size of around $5 \mu \mathrm{m}$. Some bigger vesicles were also observed with "onionlike" shapes and other vesicular structures with sizes up to $55 \mu \mathrm{m}$. Also, cryoTEM was used in the characterization of this system because it can be successfully applied to the visualization of nanometersized objects. Whereas it provides direct images with high resolution of molecules and aggregates ranging between 5 and $10 \mathrm{~nm}$ and $1 \mu \mathrm{m}$ in size, there is a limitation of the technique because the determination of size distributions is not reliable. However, together with light microscopy, it can give a very good idea of the sample characteristics. Confirming what was observed in the light microscope, polydisperse vesicles, mainly unilamellar (Figure 2b) as well as some larger multilamellar ones, were successfully visualized.

All these observations were maintained on changing the surfactant concentration. The dilution of the vesicle solution within the studied concentrations apparently did not change the shape or average size of the vesicles. In fact, we detected a difference only in terms of the number of vesicles; for the most concentrated ones, the number was much higher. In some of these, we observed at the top of the sample a more turbid solution with a higher vesicle density.

Phase Behavior of Mixtures of DNA and Positively Charged Vesicles. The interaction between DNA and vesicles with a positive net charge was investigated by the study of the phase behavior.

The difficulty of presenting the phase behavior for multicomponent surfactant-surfactant systems was mentioned above, and obviously the presence of an additional component brings 
a)

b)

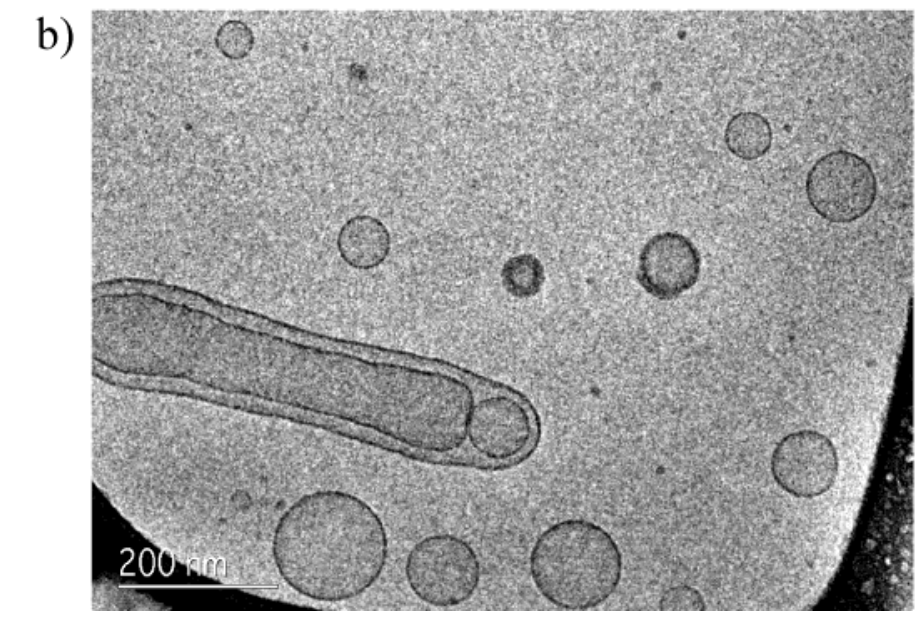

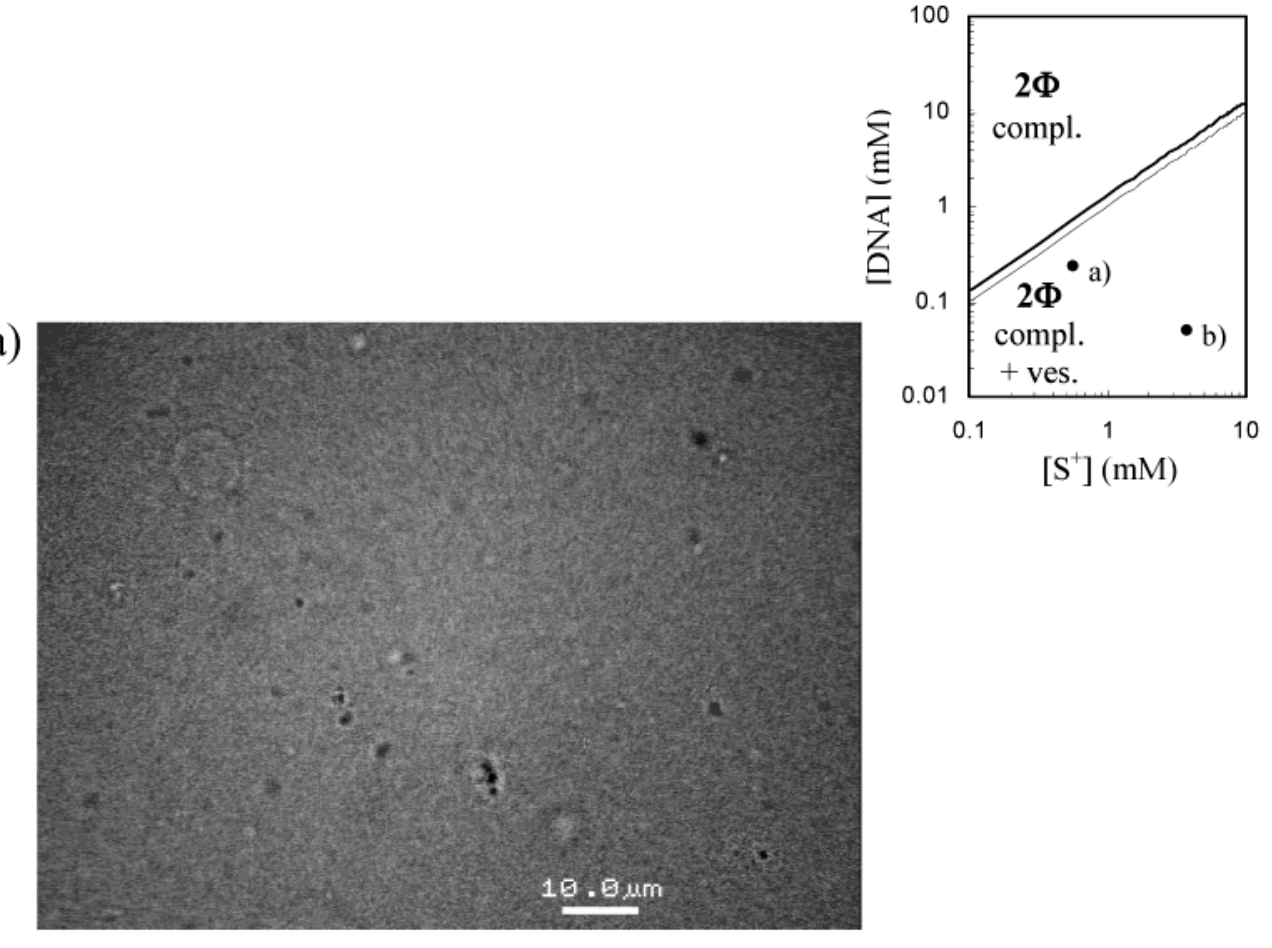

$\left[\mathrm{S}^{+}\right](\mathrm{mM})$

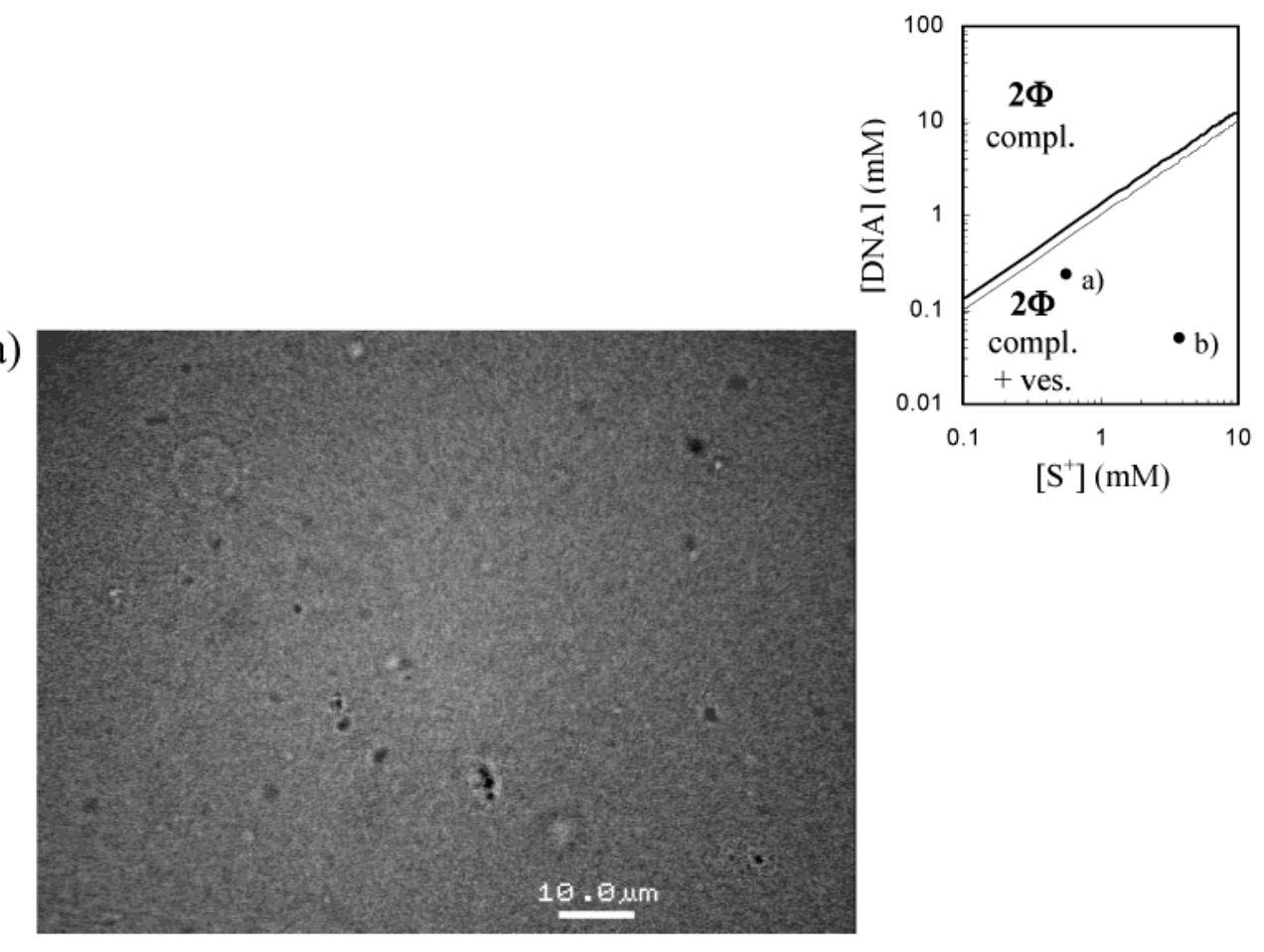

Figure 4. Light and cryo-TEM micrographs for solutions in the aqueous DNA-CTAB/SOS system: (a) $\left[\mathrm{S}^{+}\right]=0.62 \mathrm{mM}$ and $[\mathrm{DNA}]=0.25 \mathrm{mM}$, a small number of vesicles in coexistence with complexes; $(b)\left[\mathrm{S}^{+}\right]=3.77 \mathrm{mM}$ and $[\mathrm{DNA}]=0.05 \mathrm{mM}$, vesicles in coexistence with a few DNA-vesicle complexes.

further complexity to the representation of the phase behavior of the polymer-surfactant-surfactant system. As discussed, because of the fact that we are in a dilute regime and that it provides a better visualization, the phase map plotting the DNA charge concentration, [DNA], versus the net surfactant charge concentration, $\left[\mathrm{S}^{+}\right]$, is presented on a $\log -\log$ scale (Figure 3 ). It was observed earlier ${ }^{21}$ that as little as $5 \times 10^{-9} \mathrm{M}$ of DNA is enough to induce association between DNA and positively charged vesicles. Therefore, it is not surprising to observe an increase in turbidity and a concomitant phase separation for samples with very small amounts of DNA and surfactant. Two phase samples were present for all concentrations studied. It was not possible to determine with precision when exactly phase separation started because turbidity experiments were impossible to perform for these vesicle systems because of the fact that vesicle solutions already have a turbid (bluish) appearance. We can, however, say, as explained below, that DNA-vesicle complexes have already been observed for DNA concentrations of $1.0 \times 10^{-6} \mathrm{M}$.
Slightly above the charge neutralization line, for concentration ratios $[\mathrm{DNA}] /\left[\mathrm{S}^{+}\right], \mathrm{D} / \mathrm{S}$, above 1.3 , the supernatants were transparent. It should be noticed that some samples presented a bluish but translucent supernatant, and several months were necessary for the samples to become transparent. This made us believe that other kinds of aggregates, not vesicles, were present (i.e., above that mixing ratio, all vesicles were destroyed). To clarify this and other points, further observations were made by both optical and electron microscopy.

Direct Observation of Vesicle-DNA Complexes. When starting to investigate the bottom left corner of the phase diagram, we could see, by optical microscopy, that the dominant structure was a sort of aggregate, DNA-vesicle complex and that only a few free vesicles were observed in solution (Figure 4a). This is not really surprising because, as stated above, the number of vesicles for low surfactant concentrations is not high. It is interesting that the complexes were observed in solutions with such low concentrations of DNA as $1.0 \times 10^{-6} \mathrm{M}$. It was difficult to define the characteristic size of the complexes 
a)
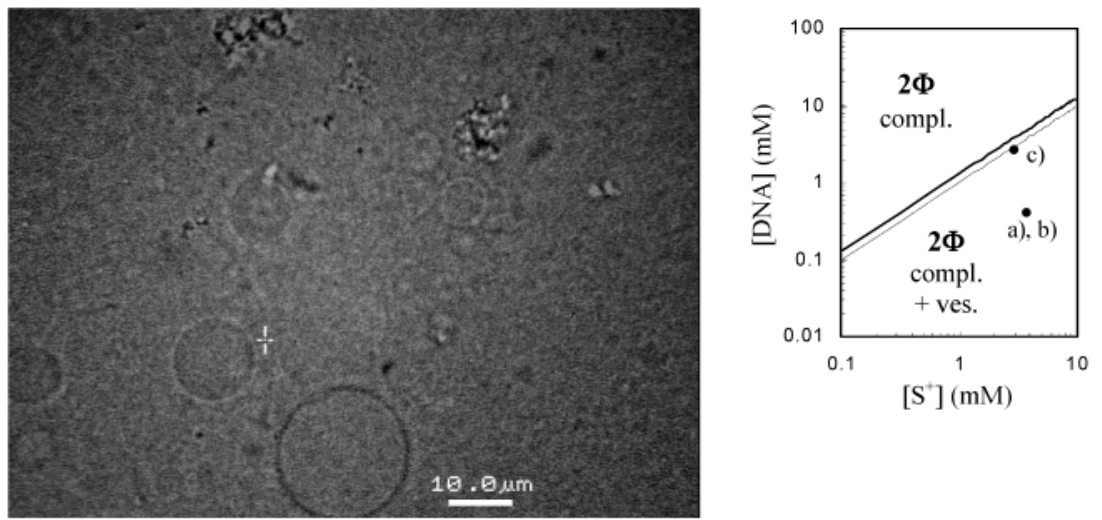

b)

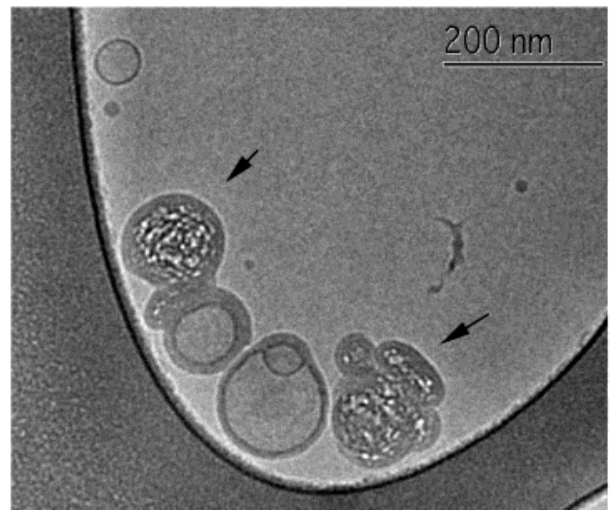

c)

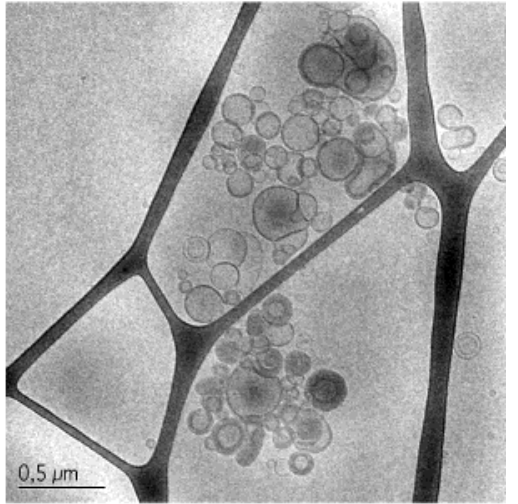

Figure 5. Light (a) and cryo-TEM (b) images for $\left[\mathrm{S}^{+}\right]=3.77 \mathrm{mM}$ and $[\mathrm{DNA}]=0.4 \mathrm{mM}$. There are a large number of DNA-vesicle complexes in coexistence with unperturbed vesicles and also some complex aggregates. (c) Cryo-TEM images for $\left[\mathrm{S}^{+}\right]=2.89 \mathrm{mM}$ and $[\mathrm{DNA}]=2.80 \mathrm{mM}$, showing aggregates of complexes in coexistence with vesicles. Arrows denote beam-damaged material.

because most of them just showed up as black spots that were too small to be detected clearly by the optical microscope (Figures 4a, 5a, and 6a).

If we move in the direction of increasing surfactant concentration, we can observe, naturally, an increase in the number of vesicles as well as in the number of complexes.

Because it is easier to detect differences under these conditions, we will focus the discussion on this region. By following the direction of increasing DNA concentration, we could mainly observe an increase in the number of complexes as we came closer to charge neutralization; furthermore, we could see the appearance of larger structures that are aggregates of the complexes mentioned above (Figure 5a). For D/S of 1.3 and higher, vesicles were no longer visible in solution; complexes and small aggregates were the dominating structures for high DNA concentrations (Figure 6a). Similar results were obtained from electron microscopy observations.

Focusing again on the higher surfactant concentration region, for low amounts of DNA, we found that the presence of the macromolecule was almost not noticeable. Some vesicles were disrupted and nonspherical, and a few others presented a thicker bilayer than usual (Figure 4b). This was due to an increase of the electron density, possibly due to the presence of DNA molecules, and it corresponded presumably to the complexes observed in optical microscopy. With an increase in DNA concentration, we observed an increase in the number of complexes still in coexistence with unperturbed vesicles (Figure $5 b)$ and also an aggregation of the complexes (Figure 5c). Finally, for $\mathrm{D} / \mathrm{S} \geq 1.3$, no more vesicles were observable.

With respect to DNA-vesicle complexes, except for very low amounts of DNA, where we could observe only small complexes with sizes between 50 and $100 \mathrm{~nm}$ (Figure 4b), all samples showed some polydispersity ranging from 50 to 300 $\mathrm{nm}$.

The cryo-TEM technique provides excellent resolution, so it was possible to identify what seemed to be a short-range lamellar structure in the DNA-surfactant complexes (Figure 7a and b). In Figure $7 \mathrm{c}$ is plotted a line profile with an integration area width given by the area shown in Figure $7 \mathrm{~b}$. This profile clearly shows a periodicity of approximately $6.1 \mathrm{~nm}$.

Structure of DNA-Catanionic Vesicle Complexes. We could establish by cryo-TEM, especially for the higher DNA concentrations, that a lamellar structure is present. To clarify this, we performed small-angle X-ray diffraction experiments. We kept the surfactant concentration, $\mathrm{S}^{+}$, constant and increased the DNA concentration, thus varying the mixing ratio, D/S. As shown in Figure 8 for one of the surfactant concentrations investigated, we clearly see a lamellar structure, as denoted by three peaks (indicated by arrows in Figure 8 ) at $0.11,0.22$, and $0.33 \AA^{-1}$. The lamellar spacing of all the samples studied is presented in Figure 9. The values ranged between 56.1 and 59.9 $\AA$. Another interesting aspect of Figure 8 is the fact that above the charge neutralization of the system, $D / S=1$, a broad peak shows up behind the first diffraction maximum and moves to higher $q$ values on increasing the DNA concentration. This was attributed, according to the literature,$^{4-6}$ to the 1D array of DNA molecules with the spacing $d_{\text {DNA }}=2 \pi / q_{\text {DNA }}$ between the lipid bilayers. The in-plane spacing between parallel DNA strands is plotted versus the DNA/vesicle charge ratio in Figure 9. We can see that $d$ is linearly dependent on $\mathrm{D} / \mathrm{S}$. 
a)

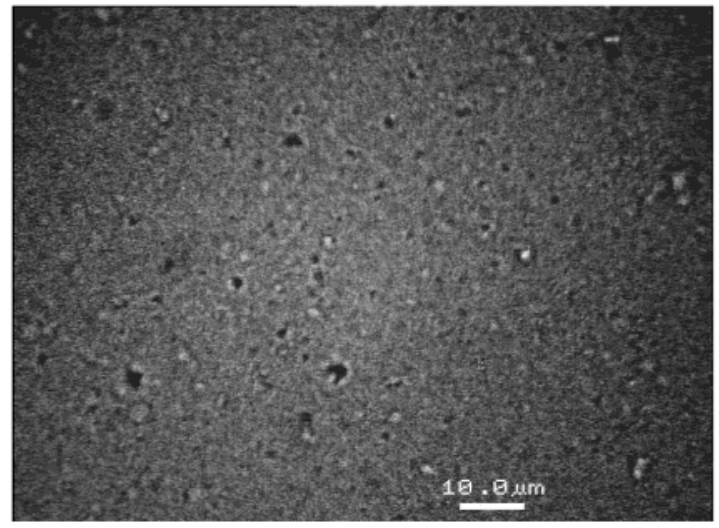

b)

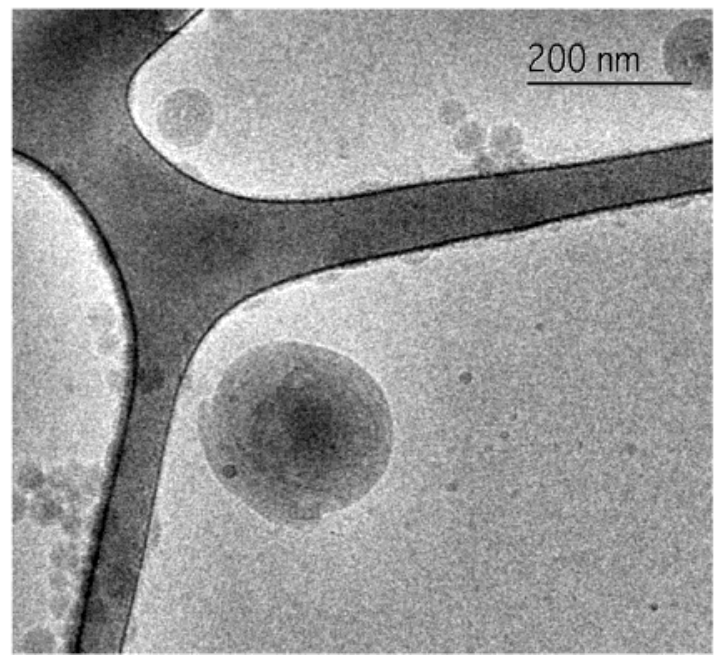

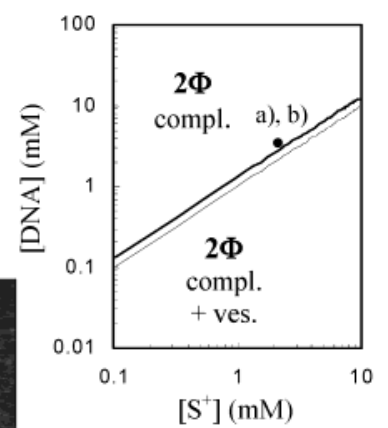

Figure 6. Light (a) and cryo-TEM (b) images for $\left[\mathrm{S}^{+}\right]=2.22 \mathrm{mM}$ and $[\mathrm{DNA}]=2.88 \mathrm{mM}$. Only DNA-vesicle complexes are present in solution.

a)

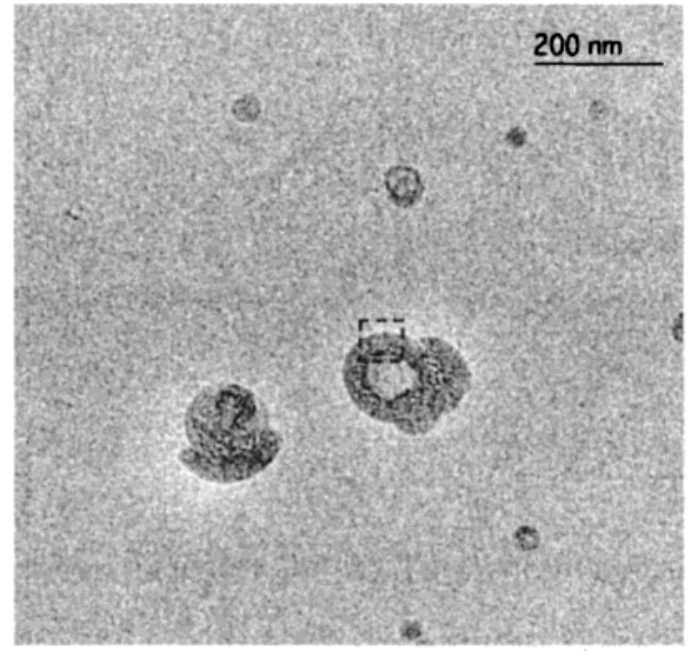

b)

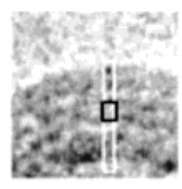

c)

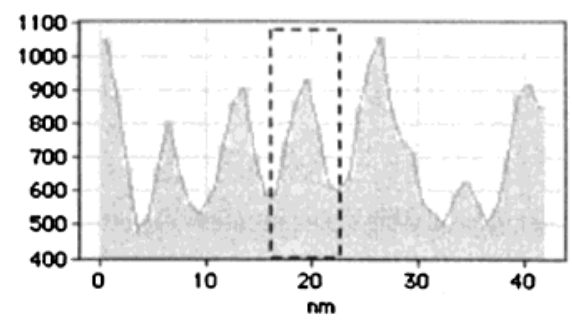

Figure 7. Multilamellar structures formed by the interaction of DNA with catanionic vesicles. (a) Cryo-TEM image of DNA-vesicle complexes; $[\mathrm{DNA}]=2.88 \mathrm{mM},\left[\mathrm{S}^{+}\right]=2.22 \mathrm{mM} ; \mathrm{D} / \mathrm{S}=1.30$. (b) Magnified detail of the lamellae details from (a). (c) Line profile with an integration-area width given by the area shown in (b).

\section{Discussion}

DNA-Vesicle Interactions. From previous experiments ${ }^{21}$ on these systems and from the literature ${ }^{3,6}$ for other similar systems, we know that very small amounts of DNA are needed for the DNA-vesicle association. The strong association is directly evident by the formation of precipitate for very low amounts 


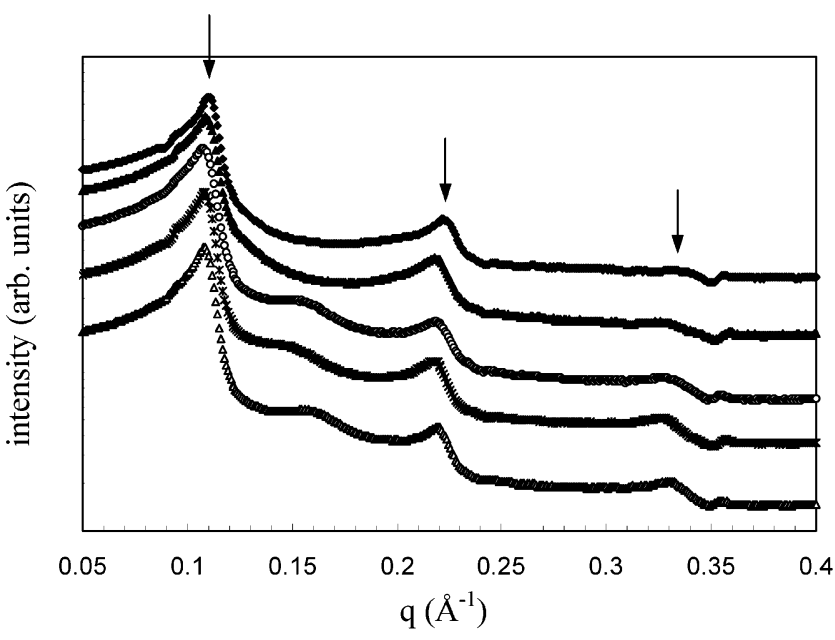

Figure 8. Small-angle X-ray diffractogram of precipitated DNA$\mathrm{CTAB} / \mathrm{SOS}$ complexes. The surfactants CTAB and SOS are in a fixed mixing ratio of 1.27 , and the total positive surfactant charge is $\mathrm{S}^{+}=$ $1.2 \mathrm{mM}$. The amount of DNA on the samples increases from the upper to the bottom curves, varying the concentration ratios $[\mathrm{DNA}] /\left[\mathrm{S}^{+}\right], \mathrm{D} / \mathrm{S}$ $(\diamond), \mathrm{D} / \mathrm{S}=0.83 ;(\boldsymbol{\Delta}), \mathrm{D} / \mathrm{S}=1.00 ;(\mathrm{O}), \mathrm{D} / \mathrm{S}=1.67 ;(*), \mathrm{D} / \mathrm{S}=2.00$; $(\triangle), \mathrm{D} / \mathrm{S}=2.50$

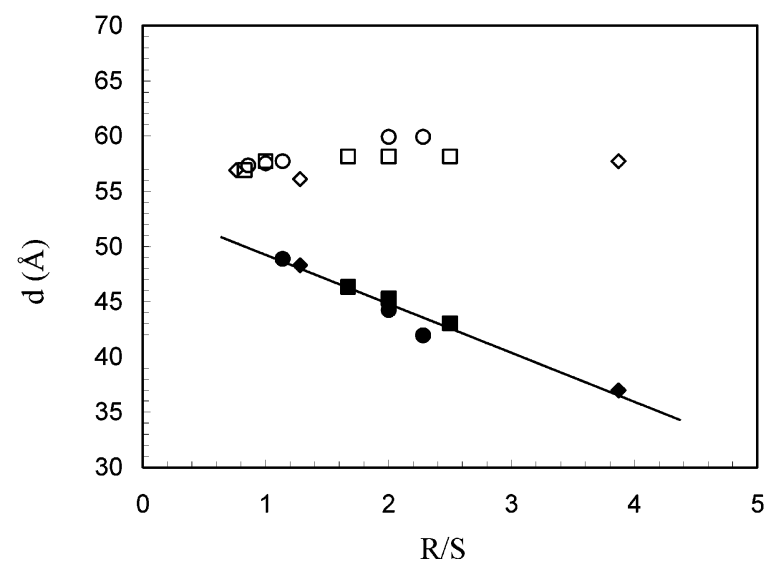

Figure 9. Repeat distances, taken from SAXS diffractograms in Figure $8 \mathrm{a}$, for the DNA-DNA spacing, $d_{\mathrm{DNA}}$ (filled symbols), and the interlayer distance, $d_{\text {mem }}$ (open symbols), as a function of the concentration ratios, $[\mathrm{DNA}] /\left[\mathrm{S}^{+}\right], \mathrm{D} / \mathrm{S}$. Different symbols correspond to different net surfactant charge concentrations: $(\mathbf{\square}),\left[\mathrm{S}^{+}\right]=1.2 \mathrm{mM} ;(\bullet),\left[\mathrm{S}^{+}\right]$ $=2.3 \mathrm{mM} ;(\bullet),\left[\mathrm{S}^{+}\right]=3.5 \mathrm{mM}$.

of DNA and amphiphiles. This is one of the reasons that this type of system can be used with relative success in cell transfections. ${ }^{3}$ In fact, we could observe the formation of complexes from $10^{-6} \mathrm{M}$ of DNA $(0.33 \mu \mathrm{g} / \mathrm{mL})$ and over all the concentration range studied. Furthermore, the complexes were found not to dissolve in an excess of DNA, in surfactant, or even in a dilution, which guarantees the stability of the complex in an aqueous medium.

Structure of DNA-Vesicle Complexes. On the basis of cryo-TEM and SAXS data, we can conclude that there are complexes with multibilayer lamellar stacks intercalated with 1D arrays of DNA strands (Figure 10). It appears then that the vesicles, spontaneously formed and thermodynamically stable, form the same type of structures as shown by other systems. ${ }^{4-8}$ Thus, these systems, being cheaper and easier to use, can be studied as models for other more expensive and apparently more complicated ones.

However, there appears to be an interesting difference between these catanionic mixtures and the mixtures of cationic and neutral lipids. Experiments ${ }^{4,5}$ as well as some theoretical

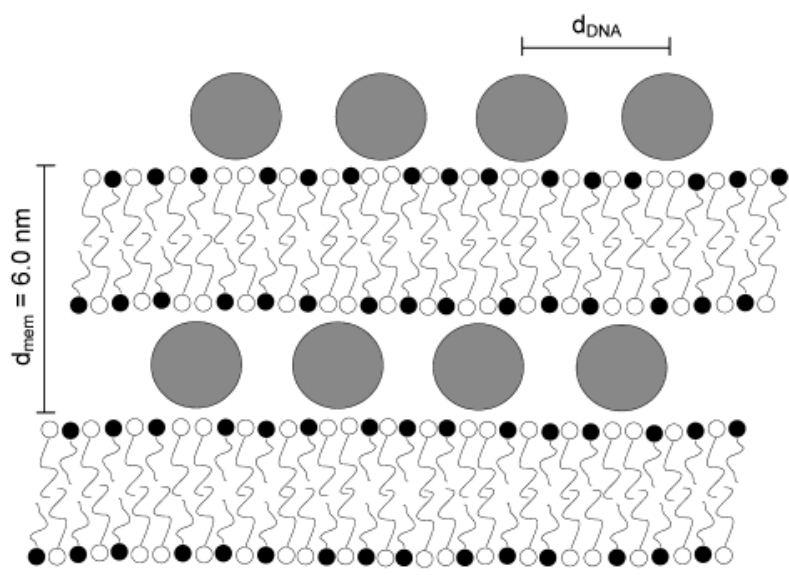

Figure 10. Schematic representation of the proposed structure for DNA-catanionic vesicle complexes.

studies $^{30,31}$ showed that by varying the DNA-to-lipid ratio (D/ $\mathrm{S})$ at constant lipid composition $(m)$ the system would pass through three different regions: for low $\mathrm{D} / \mathrm{S}$ ratios, the complexes coexist with excess liposomes and the DNA-DNA spacing $\left(d_{\mathrm{DNA}}\right)$ was nearly independent of the DNA-to-lipid ratio; for intermediate $\mathrm{D} / \mathrm{S}$ ratios, including the charge neutralization point, $D / S=1$, all of the DNA and lipid were incorporated into the lipoplex, and $d_{\text {DNA }}$ decreased linearly with $\mathrm{D} / \mathrm{S}$; finally, for higher D/S ratios, the DNA-DNA spacing was constant, and the complexes coexisted with excess DNA.

Our system presents different behavior. It is impossible to monitor $d_{\mathrm{DNA}}$ for $\mathrm{D} / \mathrm{S}$ ratios below 1.0 because the peak it is positioned behind is the first diffraction maximum. However, we can infer that we have a coexistence of complexes and vesicles from the microscopic observations, and presumably, a first region as described previously in the literature..$^{4,5,30,31}$ The difference is that we observed a linear dependence of $d_{\mathrm{DNA}}$ on $\mathrm{D} / \mathrm{S}$ over all the ratios investigated, and no third region was observed (Figure 9, filled symbols). This would mean that all DNA added in excess is being incorporated into the complexes and that the anionic surfactant is being expelled from it. We can then have a coexistence between complexes and SOS micelles instead.

If we look at the membrane spacing, $d_{\text {mem }}$ (Figure 9, open symbols), we can observe that there is some scatter, but the general trend is a slight increase with $\mathrm{D} / \mathrm{S}$ and stabilization. This can be interpreted in terms of the differences in the alkyl chain length of the two surfactants. As SOS is expelled from the bilayer and the bilayer becomes more dominated by the long alkyl-chain surfactant, the bilayer expands toward the thickness of a bilayer of CTAB alone. The highest measured $d_{\text {men }}$ was about $59.9 \AA$. By considering the lamellar structure to be exclusively composed of $\mathrm{CTAB}$, we can calculate, by the equation $l=0.15+0.127 n_{\mathrm{c}}$, the maximum length (nanometers) of a fully extended hydrocarbon chain with $n_{\mathrm{c}}$ carbon atoms. ${ }^{32}$ This way, $l(\mathrm{CTAB})=2.182 \mathrm{~nm}$. It is also known ${ }^{32}$ that a bilayer thickness is approximately $1.61_{\max }$ in the liquid state. We have then that $d_{\text {men }} \approx 3.49 \mathrm{~nm}$. By adding a DNA molecule with one hydration shell, $2.5 \mathrm{~nm}$, we obtain a value of approximately $5.99 \mathrm{~nm}$ or $59.9 \AA$, which corresponds quite well with both SAXS and cryo-TEM results. These values indicate that the structure of the DNA-vesicle complexes is the one schematically pictured in Figure 10.

The fact that we can pack DNA above the charge neutralization of the system with the expulsion of the anionic surfactant from the bilayer is interesting. It appears that the addition of a negative amphiphile to the liposomes can induce better packing 
of DNA within the lipoplexes. Because DNA compaction is an important parameter in the efficiency of gene delivery, this phenomenon could be an interesting application to other more biocompatible systems.

\section{Conclusions}

DNA interacts strongly with positively charged catanionic vesicles. DNA-vesicle complexes are formed for very low amounts of DNA and coexist with undisturbed vesicles until a DNA-to-lipid ratio, D/S, of 1.3 is reached. Above this value, no more free vesicles are observed in solution. The complexes were found to have a similar structure to that of other systems described in the literature, so it is possible to consider these complexes to be good models for more complicated DNAliposome systems, in particular because they are cheaper and easier to control.

Also, our results suggest that the inclusion of a negative amphiphile in the vesicle preparation may induce a denser packing of DNA within the lipoplex. For DNA concentrations higher than that necessary for charge neutralization, we will instead have anionic surfactant micelles in excess rather than DNA.

Acknowledgment. This work was supported by grants from Praxis XXI (PRAXIS/BD/21227/99), the Fundação para a Ciência e Tecnologia (FCT) (project Sapiens PCTI/99/QUI/ 35415), the Swedish Research Council for Engineering Sciences (TFR), the Camurus Lipid Research Foundation, and the Center for Amphiphilic Polymers (CAP) in Lund, Sweden. We thank Joachim Rädler for fruitful discussions.

\section{References and Notes}

(1) Felgner, P. L.; Gadek, T. R.; Holm, M.; Roman, R.; Chan, H. W. Wenz, M.; Northrop, J. P.; Ringold, G. M.; Danielsen, M. Proc. Natl. Acad. Sci. U.S.A. 1987, 84, 7413-7417.

(2) Simberg, D.; Hirsch-Lerner, D.; Nissin, R.; Barenholz, Y. J. Liposome Res. 2000, 10, 1-13.

(3) Lasic D. D. Liposomes in Gene Therapy; CRC Press LLC: New York, 1997.

(4) Rädler, J. O.; Koltover, I.; Salditt, T.; Safinya, C. R. Science (Washington, D.C.) 1997, 275, 810-814.

(5) Rädler, J. O.; Koltover, I.; Jamieson, A.; Salditt, T.; Safinya, C. R. Langmuir 1998, 14, 4272-4283.

(6) Lasic, D. D.; Strey, H.; Stuart, M. C. A.; Podgornik, R.; Frederik, P. M. J. Am. Chem. Soc. 1997, 119, 832-833.
(7) Gustafsson, J.; Arvidson, G.; Karlsson, G.; Almgren, M. Biochim. Biophys. Acta 1995, 1235, 305-312.

(8) Battersby, B. J.; Grimm, R.; Huebner, S.; Cevc, G. Biochim. Biophys. Acta 1998, 1372, 379-383.

(9) Templeton, N. S.; Lasic, D. D.; Frederik, P. M.; Strey, H. H.; Roberts, D. D.; Pavlakis, G. N. Nat. Biotechnol. 1997, 15, 647-652.

(10) Koltover, I.; Salditt, T.; Rädler, J. O.; Safinya, C. R. Science (Washington, D.C.) 1998, 281, 78-81.

(11) Gershon, H.; Ghirlando, R.; Guttman, S. B.; Minsky, A. Biochemistry 1993, 32, 7143-7151.

(12) Sternberg, B.; Sorgi, F. L.; Huang, L. FEBS Lett. 1994, 356, 361366.

(13) Dan, N. Biochim. Biophys. Acta 1998, 1369, 34-38.

(14) Khan, A.; Marques, E. F. Catanionic Surfactants. In Specialist Surfactants; Robb, I. D., Ed.; Blackie Academic \& Professional: London, 1997; pp 37-76.

(15) Yatcilla, M. T.; Herrington, K. L.; Brasher, L. L.; Kaler, E. W.; Chiruvolu, S.; Zasadzinski, J. A. J. Phys. Chem. 1996, 100, 5874-5879.

(16) Marques, E.; Regev, O.; Khan, A.; Miguel, M.; Lindman, B. $J$ Phys. Chem. A 1998, 102, 6746-6758.

(17) Brasher, L. L.; Herrington, K. L.; Kaler, E. W. Langmuir 1995, $11,4267-4277$

(18) Mel'nikov, S. M.; Sergeyev, V. G.; Mel'nikova, Y. S.; Yoshikawa, K. J. Chem. Soc., Faraday Trans. 1997, 93, 283-288.

(19) Mel'nikov, S. M.; Mel'nikova, Y. S.; Lofroth, J. E. J. Phys. Chem. B 1998, 102, 9367-9369.

(20) Mel'nikova, S. M.; Lindman, B. Langmuir 2000, 16, 5871-5878.

(21) Mel'nikov, S. M.; Dias, R.; Mel'nikova, Y.; Marques, E. F.; Miguel, M. G.; Lindman, B. FEBS Lett. 1999, 453, 113-118.

(22) Sambrook, J.; Fritsch, E.; Maniatis, T. Molecular Cloning: A Laboratory Manual; Cold Spring Harbor Laboratory Press: New York, 1989.

(23) Thalberg, K.; Lindman, B.; Karlström, G. J. Phys. Chem. 1991, $95,6004-6011$

(24) Jokela, P.; Jönsson, B.; Wennerström, H. Prog. Colloid Polym. Sci. 1985, 97, 4729-4735.

(25) Marques, E.; Khan, A.; Miguel, M.; Lindman, B. J. Phys. Chem. 1993, 97, 4729-4736.

(26) Dias, R.; Mel'nikov, S.; Lindman, B.; Miguel, M. G. Langmuir 2000, 16, 9577-9583.

(27) Rubbi, C. P. Light Microscopy: Essential Data; Wiley \& Sons: Chichester, U.K., 1994.

(28) Miller, D. D.; Bellare, J. R.; Evans, D. F.; Talmon, Y.; Ninham, B. W. J. Phys. Chem. 1987, 91, 674-685.

(29) Bellare, J. R.; Davis, H. T.; Scriven, L. E.; Talmon, Y. J. Electron Microsc. Tech. 1988, 10, 87-111.

(30) Harries, D.; May, S.; Gelbart, W. M.; Ben-Shaul, A. Biophys. J. 1998, 75, 159-173.

(31) Dan, N. Biophys. J. 1997, 73, 1842-1846.

(32) Evans, D. F.; Wennerström, H. The Colloidal Domain: Where Physics, Biology and Technology Meet; VCH: New York, 1999; pp 1217. 